\title{
Significance of feeding to the development of postlarval megalopae in the free-living crab Lophopanopeus bellus and commensal crab Fabia subquadrata
}

\author{
Breanna Harris, Stephen Sulkin* \\ Shannon Point Marine Center, 1900 Shannon Point Road, Anacortes, Washington 98221, USA
}

\begin{abstract}
Crab megalopae, derived from wild caught terminal stage zoeae, were reared in 'point of no return' (PNR) diet treatments consisting of progressively extended initial periods of starvation followed by continuous feeding and 'point of reserve saturation' (PRS) treatments consisting of progressively extended periods of feeding followed by continuous starvation. No unfed megalopae of either the free-living Lophopanopeus bellus or the commensal Fabia subquadrata survived to Crab I, while megalopae fed continuously on brine shrimp Artemia sp. nauplii showed high survival. Extension of initial starvation produced increased mortality and delayed molting in both species, with a PNR of $9 \mathrm{~d}$ in L. bellus and $8 \mathrm{~d}$ in F. subquadrata. Megalopae thus must initiate feeding by approximately one-half of the mean stage duration of those continuously fed. L. bellus megalopae initially fed for only one-third of the mean stage duration showed the same survival as those continuously fed, while F. subquadrata megalopae fed for only one-third of the mean stage duration showed some survival to Crab I, but required feeding for two-thirds of the mean stage duration to equal the survival of those continuously fed. Neither species showed differences in stage duration on treatments that supported development. Independence from the need to feed during the latter part of the megalopa stage may permit a more effective response to settlement cues and be beneficial to the role of the post-larva in identifying benthic settlement sites.
\end{abstract}

KEY WORDS: Megalopa feeding · Lophopanopeus bellus · Fabia subquadrata · Larval nutrition Resale or republication not permitted without written consent of the publisher

\section{INTRODUCTION}

Brachyuran crabs have a complex life cycle, consisting of a pelagic zoea larva, a transitional post-larval megalopa, and a benthic juvenile/adult. The megalopa begins as a pelagic planktonic form, which is able to swim effectively using its abdominal pleopods. However, unlike the purely pelagic zoea larval stage that precedes it, the megalopa can also crawl on the sea bottom using its 5 pairs of thoracic walking legs, an important trait, given that the megalopa eventually settles to the bottom where it undergoes metamorphosis. Although megalopae of some species have been shown to accelerate metamorphosis in the presence of environmental cues (Brumbaugh \& McConaugha 1995,
Forward et al. 1996, Rodriguez \& Epifanio 2000), such cues are not obligatory for successful metamorphosis in most species (Forward et al. 2001). Whether stimulated by settlement cues or not, individuals must move from the plankton to spend time near the bottom exploring substrate and habitat for suitable settlement sites.

This transition in habitat may affect the manner in which megalopae satisfy nutritional needs. It has been demonstrated that the zoeal stages of most species are planktotrophic, often requiring access to prey soon after hatching in order to develop normally (Paul \& Paul 1980, Anger et al. 1981, Staton \& Sulkin 1991). Although zoeae are omnivorous (e.g. Harms \& Seeger 1989, Lehto et al. 1998, Sulkin et al. 1998, Perez \& Sulkin 2004), there are specific nutritional require- 
ments that can be satisfied only by ingestion of large micro- and meso-zooplankton (Bigford 1978, Levine \& Sulkin 1984, Paul et al. 1989, Sulkin et al. 1998). Furthermore, during zoeal development, there is a premium on feeding early in each succeeding stage, with larvae that do so satisfying a 'point of reserve saturation' (PRS; sensu Anger \& Dawirs 1981) that permits completion of the stage, even if access to prey is limited thereafter (Anger \& Dawirs 1981, Staton \& Sulkin 1991).

The requirements of the megalopa are less well known. In most species, megalopae are planktotrophic, requiring prey to develop to metamorphosis. In laboratory studies, this requirement has been typically met by the use of Artemia sp. nauplii (e.g. Sulkin \& Van Heukelem 1986, Forward et al. 1996). Farrelly \& Sulkin (1988) and Hartman (1994) showed that megalopae derived from laboratory-reared zoeae of the shore crab Hemigrapsus oregonensis could survive to metamorphosis if fed only during the first half of the stage, and Forward et al. (1996) reported that Callinectes sapidus megalopae appear to be able to successfully metamorphose after entering the estuarine settlement habitat without further feeding. Thus, megalopae may not need to feed during the latter part of the stage, leaving them free to attend to the requirements of settlement in benthic habitats without needing to encounter suitable prey.

The present study addresses whether megalopae need to feed throughout the stage to survive to metamorphosis, whether early feeding is sufficient to support completed development, and whether megalopae can develop to metamorphosis if fed only during the latter part of the stage. We address these questions by exposing Day 1 megalopae, derived from late stage zoeae captured in the field and thus having fed on natural diets throughout zoeal development, to a series of point of no return (PNR) and PRS diet treatments. We tested megalopae of the free-living crab Lophopanopeus bellus (Family Xanthidae) and the commensal species Fabia subquadrata (Family Pinnotheridae).

\section{MATERIALS AND METHODS}

Obtaining megalopae. Zoeae were collected from East Sound in the inland waters north of Puget Sound, Washington, USA, on June 30 and July 13, 2004. A $0.5 \mathrm{~m}$ diameter plankton net ( $500 \mu \mathrm{m}$ mesh) was towed at $6 \mathrm{~m}$ depth for $5 \mathrm{~min}$. Samples were returned to the laboratory at the nearby Shannon Point Marine Center, where zoeae were separated from other organisms. Both samples contained both early and late stage larvae from a variety of species, but in each case one species predominated. Large zoeae were separated from the sample and identified to species according to Shanks (2001). The June sample was dominated by larvae of the shore crab Lophopanopeus bellus, while the July sample contained mostly the commensal crab Fabia subquadrata.

Late stage zoeae, initially identified by size and presence of well-developed pleopod buds, were placed in $20 \mathrm{~cm}$ diameter glass bowls in $1 \mathrm{l}$ of $5 \mu \mathrm{m}$ filtered sea water (salinity of $32 \mathrm{psu}$ ), at a concentration of approximately 300 zoeae $\mathrm{l}^{-1}$. As megalopae appeared in the cultures, they were removed and placed individually into wells of 6 -well culture trays. Each $3 \mathrm{~cm}$ diameter well contained $10 \mathrm{ml}$ of $5 \mu \mathrm{m}$ filtered sea water. Megalopae continued to be assigned to wells until all trays needed to provide 3 trays per diet treatment were filled. Experiments were initiated each day that megalopae were obtained from the cultures and care was taken to assign newly obtained individuals randomly among the treatments each day. All megalopal feeding treatments were completely set up within $3 \mathrm{~d}$ of zoeae collection. Thus all treatments included 18 Day 1 megalopae, although the Day 1 megalopae assigned to all treatments were obtained over a $3 \mathrm{~d}$ period. Zoeae were fed freshly hatched nauplii of the brine shrimp Artemia sp. (6 to 8 nauplii $\mathrm{ml}^{-1}$ ) until they molted to the megalopa.

Diet treatments. PNR treatments included continuously unfed and fed controls, plus a series in which progressive periods of initial starvation were followed by continuous feeding. PRS treatments included the same unfed and continuously fed controls, plus a series in which progressive periods of initial feeding were followed by continuous starvation. Freshly hatched Artemia sp. nauplii (6 to 8 nauplii $\mathrm{ml}^{-1}$ ) were used as food according to the treatment feeding schedule. PNR/PRS experiments for Lophopanopeus bellus included 10 such treatments (Fig. 1). Those for Fabia subquadrata were similar, except that intervals of $4 \mathrm{~d}$ each were used, due to the limited numbers of Day 1 megalopae available for testing simultaneously. The 6 treatments included unfed, continuously fed, $4 \mathrm{~d}$ initially unfed and fed and 8 d initially unfed and fed. For both species, 3 trays (18 megalopae) were assigned to each of the diet treatments.

Artemia sp. cysts (Argent Chemical Laboratories) were added to filtered, aerated sea water at room temperature for $24 \mathrm{~h}$, after which point the newly hatched nauplii were harvested and added to the appropriate diet treatments by pipette.

Diet experiments. PNR/PRS experiments were carried out on groups of Day 1 Lophopanopeus bellus and Fabia subquadrata megalopae in identical fashion, except for the scheduling of treatments as described above. Each well of each experimental tray was examined daily for evidence of molting or death. Live mega- 


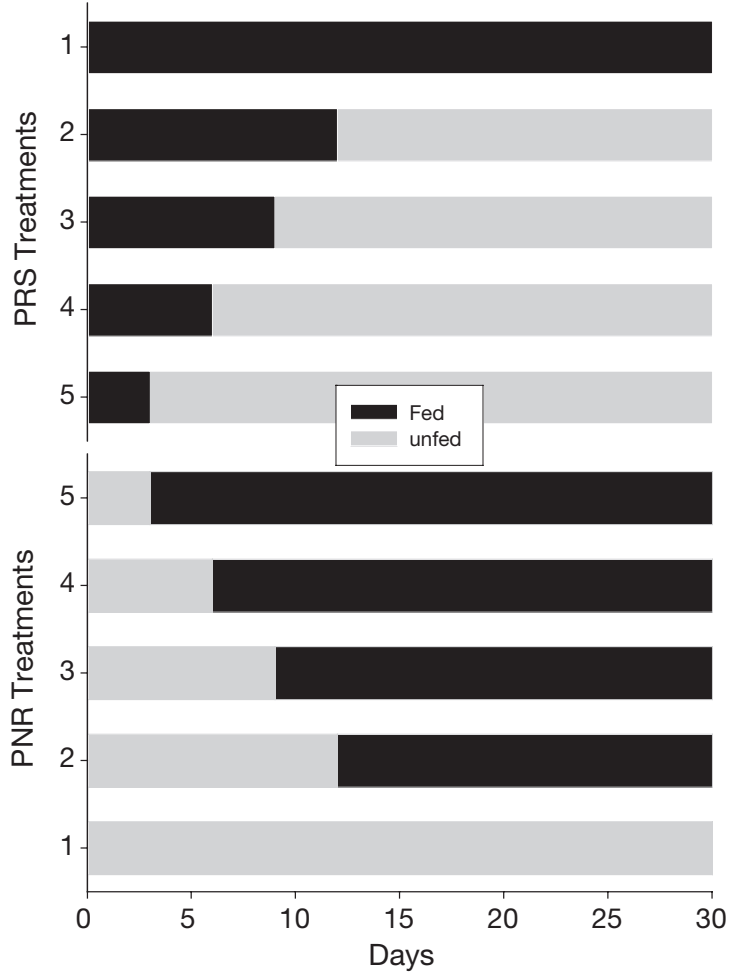

Fig. 1. Lophopanopeus bellus. PNR/PRS diet treatments, indicating relative lengths of time of fed and unfed periods for each treatment

lopae were transferred to clean wells, filled with $10 \mathrm{ml}$ of $5 \mu \mathrm{m}$ filtered seawater and, if required by the treatment's feeding schedule, fed with Artemia sp. nauplii. The experiment was continued until all megalopae had either died or molted to Crab I.

Crab I weights. For each treatment in which molting occurred in Lophopanopeus bellus, all Crab I individuals were frozen. At the conclusion of the experiment, 5 individuals from each treatment were randomly selected for weighing, using a Comparator Mettler Toledo Microscale $( \pm 0.001 \mathrm{mg})$. Individuals were placed in pre-dried and pre-weighed aluminum boats and dried for $24 \mathrm{~h}$ at $100^{\circ} \mathrm{C}$. After cooling, the boats were weighed again providing a net dry weight per individual.

Data analysis. For each experiment, daily survival was calculated and plotted as a function of time. Mean stage mortality was determined for each treatment and compared among treatments in each experiment using parametric tests after arc sine transformation of the data. Mean stage duration was calculated for those treatments in which some molting to the Crab I stage occurred and mean day of death, for those in which no molting occurred. Where such means are provided in the text, the standard error of the mean is provided in parenthesis. In all cases, Bartlett's test for equal variances was not significant $(p=0.05)$ and appropriate parametric tests were used to compare means within the experiment. Mean Crab I dry weights were analyzed in the same manner.

\section{RESULTS}

\section{Lophopanopeus bellus}

PNR experiment

Survival of megalopae decreased as the period of initial starvation was extended (Fig. 2). Megalopae fed continuously showed high survival, with mean stage duration of $18.6 \pm 0.42 \mathrm{~d}$, while no unfed megalopae survived to Crab I. Mean stage mortality increased with increase in the duration of initial starvation (Table 1). A 1-way analysis of variance (ANOVA) indicated significant differences among treatments, but a Tukey's Honestly Significant Difference (HSD) test $(p=0.05)$ failed to distinguish among treatments. Accordingly, each successive starvation treatment was compared individually to the fed control until the first significant difference was found at the $9 \mathrm{~d}$ initial starvation treatment (2 sample $t$-test, $\mathrm{p}<0.02$; Table 1).

As period of initial starvation increased, there was an extension of stage duration (Table 1). A 1-way ANOVA indicated significant differences among the means $(\mathrm{p}<$ $0.05)$, with the Tukey's HSD test $(p=0.05)$ showing significant delay in development initially at the 6 d starvation treatment. Stage duration of each subsequent succeeding treatment was significantly longer than the preceding one. There were no significant differences among treatments in dry weights of Crab I individuals (1-way ANOVA, p > 0.05; Table 1).

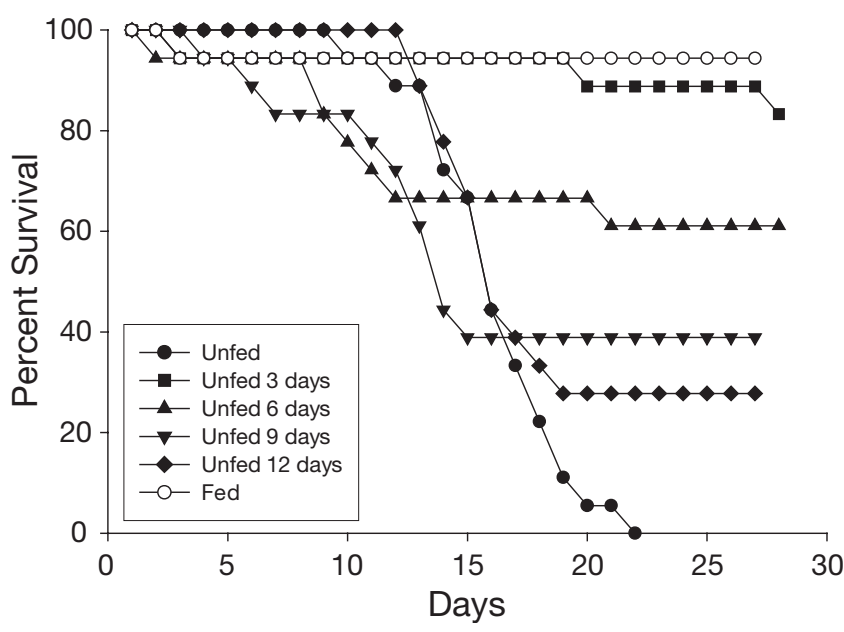

Fig. 2. Lophopanopeus bellus. Daily percent survival in megalopae fed indicated PNR diet treatments $(n=18)$ 
Table 1. Lophopanopeus bellus. Mean percent mortality, stage duration and Crab I dry weights for megalopae in the indicated PNR and PRS diet treatments. Standard errors shown in parentheses. Shared letters among PRS mortality values and both PNR and PRS stage durations within each experiment indicate no significant differences (Tukey's HSD; $p=0.05), *$ : first evidence of significant difference from fed control in mortality in PNR experiment. na: data not available

\begin{tabular}{|lrcc|}
$\begin{array}{l}\text { PNR treatments } \\
\text { Initial } \\
\text { starvation (d) }\end{array}$ & $\begin{array}{c}\text { Mortality } \\
(\%)\end{array}$ & $\begin{array}{c}\text { Stage duration } \\
(\mathrm{d})\end{array}$ & $\begin{array}{c}\text { Dry weight } \\
(\mathrm{mg})\end{array}$ \\
\hline 0 (fed) & 5.3 & $18.6(0.42) \mathrm{a}$ & $0.44(0.02)$ \\
3 & 16.3 & $20.7(0.42) \mathrm{a}$ & $0.44(0.04)$ \\
6 & 38.3 & $24.6(0.73) \mathrm{b}$ & $0.34(0.49)$ \\
9 & $60.7^{*}$ & $29.7(1.32) \mathrm{c}$ & $0.41(0.47)$ \\
12 & 75.7 & $38.0(1.08) \mathrm{d}$ & $0.31(0.03)$ \\
Unfed & 100.0 & na & na \\
PRS treatments & & & \\
Initial & Mortality & Stage duration & Dry weight \\
feeding (d) & $(\%)$ & $(\mathrm{d})$ & $(\mathrm{mg})$ \\
& $100.0 \mathrm{a}$ & na & na \\
\hline 0 (unfed) & $100.0 \mathrm{a}$ & na & na \\
3 & $27.3 \mathrm{~b}$ & $18.3(0.27)$ & $0.25(0.02) \mathrm{a}$ \\
6 & $0.0 \mathrm{~b}$ & $17.9(0.36)$ & $0.39(0.04) \mathrm{b}$ \\
9 & $5.0 \mathrm{~b}$ & $18.3(0.34)$ & $0.40(0.03) \mathrm{b}$ \\
12 & $5.0 \mathrm{~b}$ & $18.6(0.42)$ & $0.44(0.02) \mathrm{b}$ \\
Fed & & &
\end{tabular}

\section{PRS experiment}

Initial feeding for only $3 \mathrm{~d}$ did not support survival of any megalopae to Crab I (Fig. 3). Extending feeding for as much as 6 d resulted in substantially increased survival, with even higher survival seen when feeding

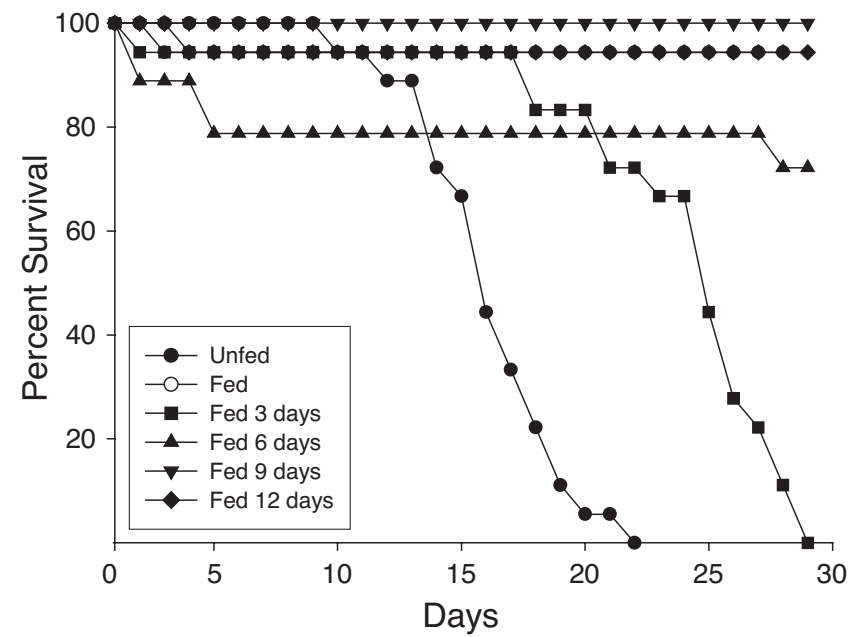

Fig. 3. Lophopanopeus bellus. Daily percent survival in megalopae fed indicated PRS diet treatments. Covered fed treatment plot same as in Fig. 2 ( $\mathrm{n}=18$ per treatment) was extended further (Fig. 3). These observations were confirmed by 1-way ANOVA comparing mean stage mortality ( $p<0.001$; Table 1$)$, with the Tukey's HSD $(p=0.05)$ indicating that all treatments in which feeding equaled or exceeded $6 \mathrm{~d}$ showed reduced mortality, although there were no differences among the groups fed more than $3 \mathrm{~d}$.

Among treatments in which molting to Crab I occurred, there were no significant differences among treatments in stage duration (1-way ANOVA, p > 0.05; Table 1). A comparison of mean dry weights among the same treatments indicated significant differences (1way ANOVA, $\mathrm{p}<0.01$ ) with Tukey's HSD ( $\mathrm{p}=0.05)$ showing a significantly lower weight for those fed for $6 \mathrm{~d}$ as compared to all other treatments (Table 1).

\section{Fabia subquadrata \\ PNR experiment}

Extending initial starvation for more than $4 \mathrm{~d}$ resulted in reduced survival, with no unfed megalopae surviving to Crab I and those fed continuously or initially starved for only $4 \mathrm{~d}$ showing high survival (Fig. 4). Continuously fed megalopae had mean stage duration of $13.7 \pm 0.53 \mathrm{~d}$ (Table 2). When mean stage mortality was compared among treatments, significant differences were found (1-way ANOVA, p < 0.001) with the Tukey's HSD test indicating a significant increase at the $8 \mathrm{~d}$ treatment $(\mathrm{p}=0.05$; Table 2). Stage duration was extended with each succeeding period of initial starvation (1-way ANOVA, p < 0.001; Tukey's HSD, $\mathrm{p}=0.05$; Table 2).

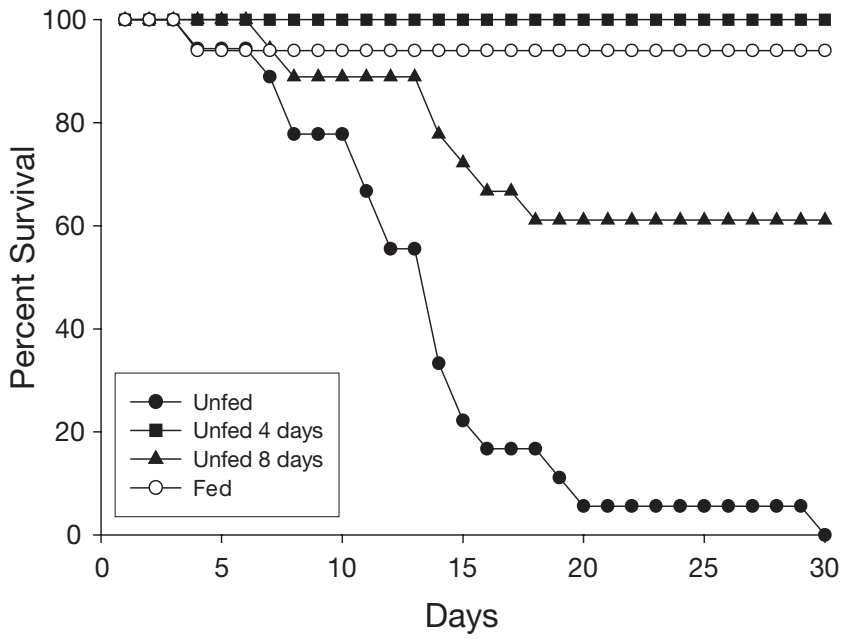

Fig. 4. Fabia subquadrata. Daily percent survival in megalopae fed indicated PNR treatments ( $\mathrm{n}=18$ per treatment) 
Table 2. Fabia subquadrata. Mean percent mortality and stage duration to Crab I for megalopae in the indicated PNR and PRS treatments. Standard errors shown in parentheses. Shared letters among percent mortality and stage duration indicate no significant differences (Tukey's HSD $; \mathrm{p}=0.05$ ). na: data not available

\begin{tabular}{|lcc|}
\hline $\begin{array}{l}\text { PNR treatments } \\
\text { Initial } \\
\text { starvation (d) }\end{array}$ & $\begin{array}{c}\text { Mortality } \\
(\%)\end{array}$ & $\begin{array}{c}\text { Stage duration } \\
(\mathrm{d})\end{array}$ \\
\hline 0 (fed) & $5.3 \mathrm{a}$ & $13.7(0.53) \mathrm{a}$ \\
4 & $0.0 \mathrm{a}$ & $17.5(0.46) \mathrm{b}$ \\
8 & $38.7 \mathrm{~b}$ & $23.1(0.97) \mathrm{C}$ \\
Unfed & $100.0 \mathrm{C}$ & na \\
PRS treatments & & Stage duration \\
Initial & Mortality & $(\mathrm{d})$ \\
feeding (d) & $(\%)$ & na \\
\hline 0 (unfed) & $100.0 \mathrm{a}$ & $13.0(1.38)$ \\
4 & $69.7 \mathrm{~b}$ & $13.5(0.55)$ \\
8 & $6.7 \mathrm{C}$ & $13.7(0.53)$ \\
fed & $5.3 \mathrm{c}$ & \\
\hline
\end{tabular}

PRS experiment

An initial feeding period of only $4 \mathrm{~d}$ (approximately $30 \%$ of mean stage duration of continuously fed megalopae) resulted in decreased survival, although $8 \mathrm{~d}$ of initial feeding showed little difference from continuously fed controls (Fig. 5). This was confirmed by comparison of mean stage mortality among treatments (Table 2), with mortality the same in continuously fed megalopae and those fed for $8 \mathrm{~d}$, an increase in mortality in those fed for only $4 \mathrm{~d}$ and $100 \%$ mortality in unfed megalopae (ANOVA, $\mathrm{p}<0.01$; Tukey's HSD, $\mathrm{p}=$

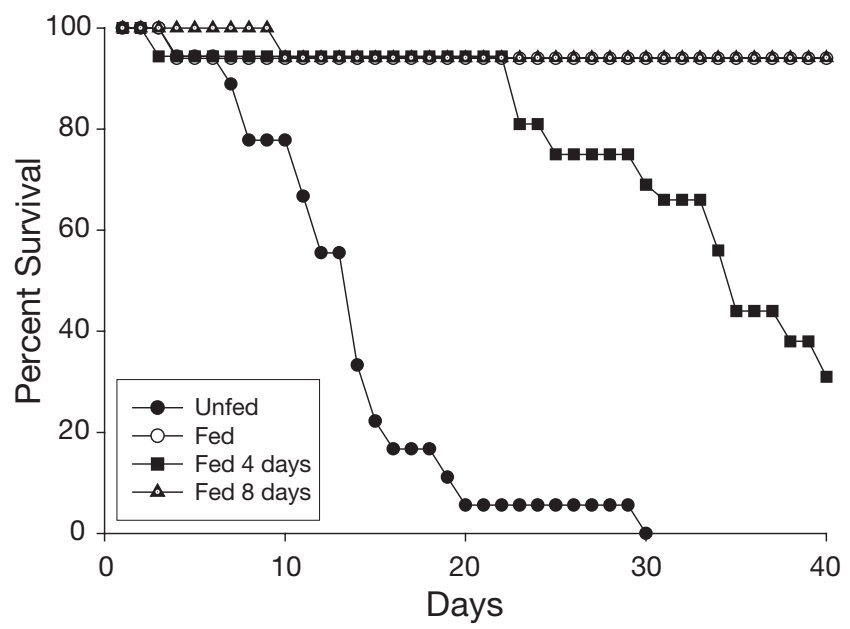

Fig. 5. Fabia subquadrata. Daily percent survival in megalopae fed indicated PRS treatments. Covered fed treatment plot same as Fig. 4 ( $\mathrm{n}=18$ per treatment)
0.05). Among those megalopae that successfully developed to Crab I, there were no significant differences in time to molt among treatments (ANOVA, $\mathrm{p}>0.05$ ).

\section{DISCUSSION}

Results of the present study are consistent with those reported for megalopae of Hyas araneus (Anger \& Dawirs 1982) and Hemigrapsus oregonensis (Farrelly \& Sulkin 1988, Hartman 1994). Unlike previous studies in which Day 1 megalopae had been derived from laboratory-raised zoeae, megalopae used in the present study were derived from wild-caught terminal stage zoeae that had developed on naturally occurring nutritional sources, thus entering the megalopa stage in a condition which very closely simulated natural conditions. Nevertheless, it is clear that megalopae of both Lophopanopeus bellus and Fabia subquadrata must feed at some point during the stage to molt to Crab I. Furthermore, in both species, a period of early feeding is sufficient to support completed development. In $L$. bellus, initial feeding for only one-third of the average stage duration (18.6 d) proved sufficient to support survival equal to that of continuously fed megalopae. Moreover, there was no delay in development to Crab I for megalopae fed for only the first $6 \mathrm{~d}$, although there may be a reduction in weight. A similar result was seen in $F$. subquadrata, although initial feeding for approximately $58 \%$ of the average stage duration was required to support survival equal to that of continuously fed megalopae. The lower precision in treatment intervals may be responsible for some of this apparent difference between species. Nevertheless, there is no effect on stage duration for megalopae initially fed for only $8 \mathrm{~d}$. Thus, as previously reported for other species, there is a 'point of reserve saturation' after which continued feeding does not affect survival or time to molt in L. bellus and F. subquadrata.

Moreover, our results confirm that early starvation can both reduce survival directly and delay metamorphosis. Anger (1987a) identified a critical period early in the premolt $\left(D_{0}\right)$ that occurs between one-third and one-half of the duration of Stage 1 zoeae, during which larvae must feed in order to proceed normally through the molt cycle. Anger (1987b) further suggested that if megalopae are denied food during the entire $D_{0}$ period, biomass loss may be sufficient to prevent development to Crab I. In both Lophopanopeus bellus and Fabia subquadrata, extended periods of early starvation produced increased mortality. If feeding was initiated as early as about one-third of the average stage duration in both species, however, mortality did not significantly increase over continuously fed megalopae. In both cases, any extension of initial starvation 
resulted in prolongation of the stage, even in treatments in which mortality did not increase. This result is consistent with that of Hartman (1994) for Hemigrapsus oregonensis, and suggests that overall mortality to metamorphosis may be higher under these conditions due to an extended time in the plankton.

These results have ecological and developmental implications for the transitional megalopa stage. The stage is derived from the terminal zoeal stage which is planktonic and, in most species, planktotrophic. The terminal zoeal and early megalopa (intermolt) stages initially share the same habitat and will presumably have access to the same prey fields. Megalopae are thus likely to encounter suitable prey early in the stage and can readily satisfy nutritional needs. Although the prey used in the present experiments, Artemia sp. nauplii, is not naturally occurring, it is a good analog for the types of prey that larvae typically feed on in nature; namely, small zooplankton such as barnacle and copepod nauplii and larvae of other invertebrates. Indeed, like the zoeal stages that precede them, megalopae appear to be omnivorous, able to ingest phytoplankton, although a diet consisting strictly of algae will not sustain them (e.g. Sulkin et al. 1998). However, as megalopae approach settlement and move to the benthos, the types of prey they will encounter will likely change and suitable prey may not be as readily available. Furthermore, not needing to encounter prey may be beneficial to a megalopa whose primary function is seeking suitable habitat for the juvenile stage. Thus, independence from the need to feed as settlement approaches may provide a substantial advantage.

Settlement habitat differs markedly between the 2 species tested in the present study. The free-living Lophopanopeus bellus settles in and inhabits lower intertidal regions in the inland waters of the Puget Sound basin. Such sites are characterized by small cobble and sand and cover wide areas of both the mainland and the many islands that are located in the region. Fabia subquadrata, on the other hand, lives commensally in bivalves such as the horse mussel Modiolus modiolus, its primary host in local waters (Pearce 1966). While such hosts are common, their distribution is patchy and locating a suitable host site would presumably be more problematic for F. subquadrata megalopae. However, the present study demonstrates that substrate cues are not obligatory for either species to develop successfully to Crab I and both demonstrate independence from the need to feed as settlement approaches.

Although most crab species reared in the laboratory can proceed to metamorphosis in the absence of substrate-specific cues, there is a growing literature that suggests such cues may accelerate the settlement process (reviewed in Forward et al. 2001). Forward et al. (2001) suggest that time to metamorphosis determined for megalopae raised in clean containers using filtered seawater may represent the maximum stage duration, with environmental cues accelerating the process in nature. Cues implicated in accelerating metamorphosis are typically chemical in nature (Rodriguez \& Epifanio 2000, Forward et al. 2001). However, experiments that would elicit chemical cues have not shown acceleration effects in Cancer magister (Fernandez et al. 1994, Hora 2001). Direct observation and anecdotal evidence suggest that such megalopae may be responding to stimuli elicited when they are removed from the plankton and placed into small containers, perhaps simulating arrival in benthic settlement sites. Whatever the nature of the stimulus in specific cases, however, it seems likely that megalopae of many species reach a stage of development after which settlement can occur (competence) and that such settlement may be either enabled or promoted by environmental cues, either chemical or physical. It is appropriate to speculate that this point of competence is related to the point of reserve saturation. Satisfying nutritional needs during the early, planktonic part of the megalopa stage may therefore both enable exploration of suitable settlement sites and permit acceleration of metamorphosis when such sites are encountered.

Acknowledgements. The first author was supported by a grant from the National Science Foundation (OCE-0097190). We thank K. Shaber for assistance in the laboratory and N. Schwarck for assistance with collection of zoeae in the field.

\section{LITERATURE CITED}

Anger K (1987a) The $\mathrm{D}_{\mathrm{o}}$ threshold: a critical point in the larval development of decapod crustaceans. J Exp Mar Biol Ecol 108:15-30

Anger K (1987b) Energetics of spider crab Hyas araneus megalopa in relation to temperature and the molt cycle. Mar Ecol Prog Ser 36:115-122

Anger K, Dawirs R (1981) The influence of starvation on the larval development of Hyas areneus (Decapoda, Majidae). Helgol Wiss Meeresunters 34:287-311

Anger K, Dawirs R (1982) Elemental composition (C, N, H) and energy in growing and starving larvae of Hyas araneus (Decapoda, Majidae). Fish Bull USA 80:419-433

Anger K, Dawirs R, Anger V, Costlow J (1981) Effects of early starvation periods on zoeal development of brachyuran crabs. Biol Bull (Woods Hole) 161:199-212

Bigford T (1978) Effect of several diets on survival, development time, and growth of laboratory-reared spider crab, Libinia emarginata, larvae. Fish Bull USA 76:59-64

Brumbaugh R, McConaugha J (1995) Time to metamorphosis of blue crab Callinectes sapidus megalopae: effects of benthic microalgae. Mar Ecol Prog Ser 129:113-118

Farrelly C, Sulkin S (1988) Effect of starvation on megalopal development in the brachyuran crab Hemigrapsus oregonensis. J Crustac Biol 8:614-617 
Fernandez M, Iribarne O, Armstrong D (1994) Ecdysial rhythms in megalopae and first instars of the Dungeness crab Cancer magister. Mar Biol 118:611-615

Forward R, DeVries M, Rittschof D, Frankel D, Bischoff J, Fisher C, Welch J (1996) Effects of environmental cues on metamorphosis of the blue crab Callinectes sapidus. Mar Ecol Prog Ser 131:165-177

Forward R, Tankersley R, Rittschof D (2001) Cues for metamorphosis of brachyuran crabs: an overview. Am Zool 41: 1108-1122

Harms J, Seeger B (1989) Larval development and survival in seven decapod species (Crustacea) in relation to laboratory diet. J Exp Mar Biol Ecol 133:129-139

Hartman M (1994) Effect of exposure of ovigers to petroleum hydrocarbons on subsequent zoeal development of the brachyuran crab Hemigrapsus oregonensis using diet as an experimental tool. MS thesis, Western Washington University, Bellingham, WA

Hora B (2001) Dietary requirements and settlement ecology of the larvae and post-larvae of the brachyuran crabs Cancer oregonensis and Cancer magister. MS thesis, Western Washington University, Bellingham, WA

Lehto J, Sulkin S, Strom S, Johnson D (1998) Protists and detrital particles as prey for the first larval stage of the brachyuran crab Hemigrapsus oregonensis. J Exp Mar Biol Ecol 230:213-224

Levine D, Sulkin S (1984) Nutritional significance of longchain polyunsaturated fatty acids to the zoeal development of the brachyuran crab Eurypanopeus depressus Smith. J Exp Mar Biol Ecol 81:211-223

Editorial responsibility: Charles Peterson (Contributing Editor), Morehead City, North Carolina, USA
Paul A, Paul J (1980) The effect of early starvation on later feeding success of king crab zoeae. J Exp Mar Biol Ecol 44: $247-251$

Paul A, Paul J, Coyle K (1989) Energy sources for first-feeding zoeae of king crab Paralithodes camtschatica (Tilesius) (Decapoda: Lithodidae). J Exp Mar Biol Ecol 130:55-69

Pearce J (1966) The biology of the mussel crab Fabia subquadrata from the waters of the San Juan Archipelago, Washington. Pac Sci 20:3-35

Perez M, Sulkin S (2004) Palatability of autotrophic dinoflagellates to newly hatched larval crabs. Mar Biol 146:771-780

Rodriguez R, Epifanio C (2000) Multiple cues for induction of metamorphosis in larvae of the common mud crab Panopeus herbstii. Mar Ecol Prog Ser 195:221-229

Shanks A (2001) Identification guide to larval marine invertebrates of the Pacific Northwest. Oregon State University Press, Corvallis, OR

Staton J, Sulkin S (1991) Nutritional requirements and starvation resistance in larvae of the brachyuran crabs Sesarma cinereum (Bosc) and S. reticulatum (Say). J Exp Mar Biol Ecol 152:271-284

Sulkin S, Van Heukelem W (1986) Variability in the length of the megalopal stage and its consequence to dispersal and recruitment in the portunid crab Callinectes sapidus Rathbun. Bull Mar Sci 39:269-278

Sulkin S, Lehto J, Strom S, Hutchinson D (1998) Nutritional role of protists in the diet of first stage larvae of the Dungeness crab Cancer magister. Mar Ecol Prog Ser 169: $237-242$

Submitted: September 9, 2004; Accepted: December 3, 2004 Proofs received from author(s): April 12, 2005 